\title{
Temporal variation in early mortality of an intertidal barnacle
}

\author{
Jeremiah N. Jarrett* \\ Department of Biological Sciences, Central Connecticut State University, PO Box 4010, New Britain, Connecticut 06050, USA
}

\begin{abstract}
During the period following settlement to the substratum and preceding metamorphosis, dispersive larval stages of marine invertebrates must undergo a physiologically demanding metamorphosis, after which juveniles are exposed to new environmental conditions. Given that the intensity of biological and physical disturbance and larval physiological quality can vary over time, it would be expected that survival and growth would also vary among daily cohorts of settlers arriving to the benthic habitat. The objectives of this field study were to determine the extent to which daily cohorts of settlers of the barnacle Semibalanus balanoides differ in early post-metamorphic (i.e., juvenile) growth and survival, and to compare mortality of early juveniles and newly attached, pre-metamorphic individuals (i.e., cyprids). Mean mortality of all individuals $30 \mathrm{~d}$ after settlement differed significantly among the 5 daily cohorts examined, ranging from 29.9 to $70.2 \%$. Mean mortality also differed significantly among the 5 daily cohorts for cyprids (range 15.3 to $43 \%$ ) and juveniles (range 7.1 to $30.8 \%$ ), indicating that mortality of cyprids is generally at least as great as early juvenile mortality. Mean juvenile growth differed significantly among the 4 cohorts examined, with cohorts arriving during the beginning of the recruitment season exhibiting the fastest growth. These results support previous reports of significant variation in mortality and growth among daily cohorts of barnacles. It is proposed that temporal variation in cyprid mortality may weaken the strength of the relationship between larval abundance and recruitment for populations of marine invertebrates.
\end{abstract}

KEY WORDS: Barnacles $\cdot$ Semibalanus balanoides $\cdot$ Early post-settlement mortality · Larval settlement $\cdot$ Recruitment

$$
\text { Resale or republication not permitted }
$$

without written consent of the publisher

Patterns of adult abundance and distribution in benthic marine communities are often determined by postsettlement processes such as dislodgement, predation, competition, and physical stress (Foster 1971, Menge

\footnotetext{
*E-mail: jarrettj@ccsu.edu
}

1976, Bertness 1989, Raimondi 1990, Gosselin \& Chia 1995), and pre-settlement processes including larval transport, planktonic predation, and food limitation (Hawkins \& Hartnoll 1982, Roughgarden et al. 1991, Fenaux et al. 1994, Morgan 1995). In the absence of strong post-settlement mortality, several studies have revealed the importance of variable recruitment in determining adult abundance (Connell 1985, Raimondi 1990, Minchinton \& Scheibling 1991). Mortality before recruitment (i.e., before a juvenile is counted) can occur at 2 stages of the life cycle: pre-metamorphosis and post-metamorphosis. However, mortality at these 2 stages is not usually distinguished.

Only recently have studies begun to examine the importance of the brief period following settlement and preceding recruitment. It is during this period that the dispersive larval stage of marine invertebrates must undergo a physiologically demanding metamorphosis and the newly metamorphosed juvenile is exposed to new environmental conditions unlike those previously experienced in the plankton (Gosselin \& Qian 1996). Mortality occurring at settlement may be influenced by external factors such as dislodgement, desiccation, and predation, as well as by the physiological condition of the larvae such as energy reserves to support metamorphosis, developmental abnormalities, and parasite load (Connell 1961, Foster 1971, Pineda 1994, Gosselin \& Qian 1997, Hunt \& Scheibling 1997, Jarrett \& Pechenik 1997). Mortality of newly metamorphosed juveniles may also be affected by these external factors as well as by their physiological condition and size resulting from larval experiences such as food limitation and metamorphic delay (Pechenik et al. 1998, Pechenik 1999). These factors can thus ultimately impact recruitment through effects on metamorphic success, juvenile growth, and juvenile survival. 
Given that larval physiological quality and physical and biological disturbance may vary over time, it would be expected that survival and growth of daily cohorts would also vary temporally. The objectives of this study were to (1) determine the extent to which daily cohorts of the barnacle Semibalanus balanoides differ in early juvenile growth and survival, (2) compare the magnitude of mortality of newly attached cyprids and early juveniles, and (3) examine the relationship between cyprid and juvenile mortality.

Materials and methods. Field studies were conducted at the Marine Science Center, Northeastern University, Nahant, Massachusetts, USA, during the 1995 spring settlement season (April to May). Twelve quadrats (9.5 cm diameter), separated horizontally by approximately $20 \mathrm{~cm}$, were randomly established between 1.8 and $2.3 \mathrm{~m}$ above mean low water (an area typically occupied by adult Semibalanus balanoides) by drilling 2 bolts into the rock marking the top and bottom of each quadrat. To identify each quadrat and serve as fixed points of reference, 2 numbered tags $(2 \times 8 \mathrm{~mm})$ were glued to the center of each quadrat.

Quadrats were cleared before the onset of barnacle settlement, and 5 daily cohorts of Semibalanus balanoides were monitored from their time of attachment until 30 d later. All quadrats were photographed during the low tide on at least 5 consecutive days after each daily cohort settled, and the positions of all attached cyprids and the numbered tags were mapped so that newly attached cyprids could be positively identified. A $35 \mathrm{~mm}$ camera with a $9.5 \mathrm{~cm}$ diameter mount was fitted over the fixed bolts marking each quadrat to enable exact positioning in successive photographs. Quadrats were then photographed every few days for the next $25 \mathrm{~d}$ to monitor cyprid and juvenile mortality (5 to 9 quadrats per daily cohort, 3 to 33 ind. quadrat ${ }^{-1}$ ). Mortality was monitored for $30 \mathrm{~d}$ because it had previously been demonstrated that most juvenile mortality for $S$. balanoides occurs within the main settlement period (Minchinton \& Scheibling 1993). In the present study, the $30 \mathrm{~d}$ period following attachment extends beyond the main settlement period, even for the earliest settling cohort examined.

During the study, most cyprids metamorphosed within $1 \mathrm{~d}$ of attachment and no cyprid was observed to remain attached more than $3 \mathrm{~d}$ and still successfully metamorphose. Cyprids were considered dead if they failed to metamorphose or disappeared from the substrate on any day following attachment. Although it is possible that cyprids may detach and reattach at another location, in a previous study (Jarrett \& Pechenik 1997) none of the approximately 1200 newly attached cyprids brought to the laboratory for growth studies was observed to detach from the settlement plates. Therefore, it is reasonable to assume that a cyprid that has disappeared from a quadrat has died due to either predation or dislodgment. Metamorphosed juveniles were considered dead only if they disappeared from the substrate or were lacking their tergal and scutal shell plates.

Total mortality (cyprids and juveniles) of daily cohorts in each quadrat was calculated as the number of dead individuals during the first $30 \mathrm{~d}$ post-attachment divided by the original number of cyprids attached. Mortality of juveniles in each quadrat was estimated as the proportion of successfully metamorphosed juveniles that died during the $30 \mathrm{~d}$ post-settlement period. Cyprid mortality was calculated as the number of cyprids in each quadrat that disappeared or failed to metamorphose within $3 \mathrm{~d}$ of attachment divided by the number of originally attached cyprids. For all mortality measures, percent data were arcsinetransformed prior to analysis of variance (ANOVA). To improve the arcsine transformation, \% mortality estimates were replaced by $(X+3 / 8) /(n+3 / 4)$, where $X$ equals the number not surviving and $n$ equals the original number of individuals (Zar 1984).

Growth rates $\left(\mu \mathrm{m} \mathrm{d}^{-1}\right)$ of juveniles not in contact with other juveniles were determined by measuring the basal diameters of specific individuals between the ages of 9 and $24 \mathrm{~d}$. The focal framer was mounted with a scale bar so that caliper measurements could be converted to actual $\mu \mathrm{m}$. The outcome of interactions among sessile organisms competing for space is often controlled by differences in individual growth rates; therefore, I examined absolute growth (Jarrett \& Pechenik 1997). Because juvenile growth rates were influenced by initial juvenile size at first measurement, analysis of covariance was used to test for significant effects of attachment date, using initial juvenile size as a covariate (Zar 1984).

Results. Cyprid and juvenile mortality: Total mortality of Semibalanus balanoides during the first $30 \mathrm{~d}$ following attachment was monitored for 5 daily cohorts and ranged from 29.9 to $70.2 \%$ during the 1995 recruitment season. ANOVA revealed significant differences in total mortality among cohorts $\left(F_{4,33}=7.52, \mathrm{p}<\right.$ $0.001)$, with mortality being greatest for cohorts attaching in the middle of the season (Fig. 1). Cyprid mortality also differed significantly among cohorts $\left(F_{4,33}=\right.$ $4.23, \mathrm{p}<0.01$ ), with only the cohort arriving on 12 April having significantly lower mortality compared with the 20 April and 4 May cohorts (Tukey HSD multiplecomparison test, $\mathrm{p}<0.05$ for both comparisons). Juvenile mortality also differed among cohorts $\left(F_{4,33}=6.13\right.$, $\mathrm{p}<0.001$ ), with mortality for the 15 May cohort being significantly lower than that for the 12 April, 20 April, and 4 May cohorts (Tukey HSD multiple-comparison test, $\mathrm{p}<0.05$ for each comparison). Cyprid mortality was greater than juvenile mortality for 4 of the 5 co- 


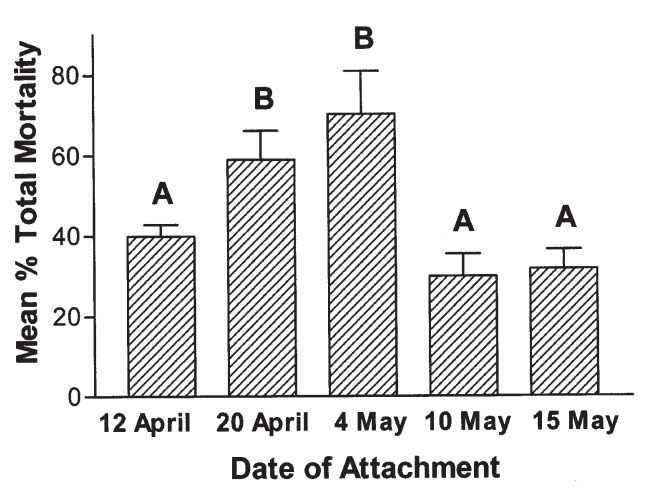

Fig. 1. Semibalanus balanoides. Mean (+SE) percentage of total mortality (cyprids plus juveniles) during first $30 \mathrm{~d}$ post-attachment for 5 daily cohorts. Bars with identical letters represent nonsignificant groupings based on Tukey's HSD multiple-comparison test following ANOVA $(p<0.05)$

horts, and cyprid mortality was significantly greater than juvenile mortality for 1 cohort (15 May, Student's $t=3.33, \mathrm{p}<0.005$, Fig. 2). In contrast, juvenile mortality was significantly greater than cyprid mortality for the 12 April cohort $(t=2.57, \mathrm{p}<0.05)$. Juvenile mortality did not appear to be influenced by cyprid mortality (linear regression, $\mathrm{r}^{2}=0.30, F_{1,3}=1.26, \mathrm{p}=0.34$ ).

Juvenile growth: Because growth rates for only 2 juveniles could be measured for the 4 May cohort, this cohort was not included in the analysis of juvenile growth. Juvenile growth rates differed significantly among the 4 cohorts (50 to 53 ind. cohort ${ }^{-1}, F_{3,199}=$ 10.90, p < 0.0001), with the April cohorts generally having greater mean juvenile growth rates than the 2 cohorts attaching in May (Fig. 3).

Discussion. The results presented here for Semibalanus balanoides support previous reports of significant variation in early juvenile survival among daily cohorts

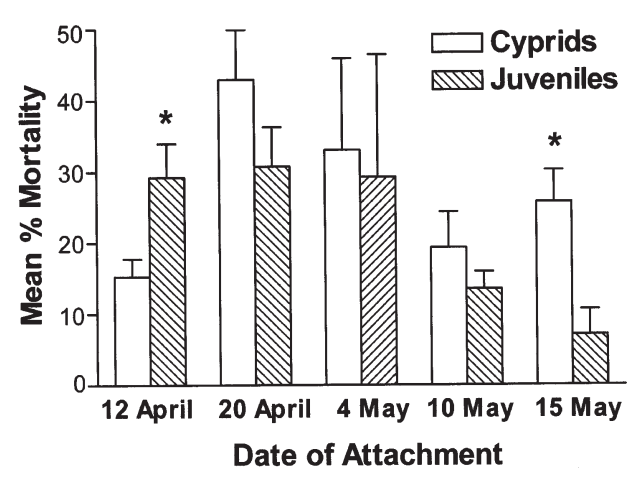

Fig. 2. Semibalanus balanoides. Mean (+SE) percentage of mortality of cyprids and early juveniles for 5 daily cohorts. Asterisks indicate significant differences between cyprid and juvenile mortality within the same cohort (Student's t-test, $\mathrm{p}<0.05$ )

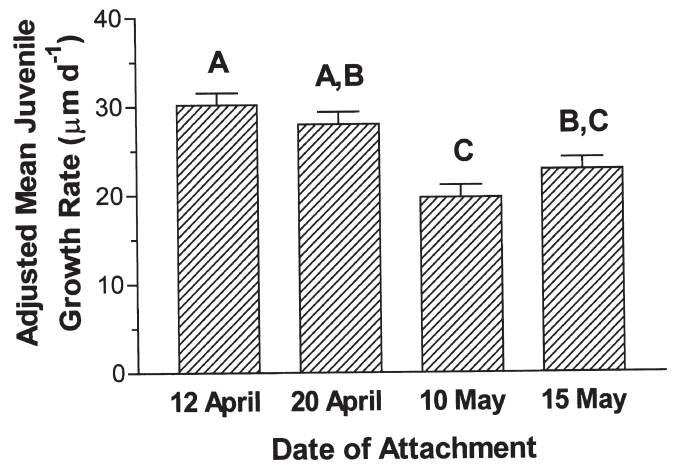

Fig. 3. Semibalanus balanoides. Juvenile growth rate $(+\mathrm{SE})$ (adjusted least-squares mean) for 4 daily cohorts. Bars with identical letters indicate nonsignificant groupings based on Tukey's HSD multiple-comparison following ANCOVA $(\mathrm{p}<$ $0.05)$

of barnacles (Connell 1961, Wethey 1984, Raimondi 1990, Gosselin \& Qian 1996). In addition, they confirm that juvenile growth rates differ among daily cohorts of $S$. balanoides in the field under natural conditions as well as in the laboratory under controlled conditions (Jarrett \& Pechenik 1997). Because individual size can influence vulnerability to predation (Connell 1961, Paine 1974, Miller \& Carefoot 1989) and dislodgment (Connell 1961, Petraitis 1983) as well as the outcome of competitive interactions (Connell 1961, Bertness 1989), differences in growth rate may ultimately result in considerable variation among daily cohorts in survival and recruitment success. Interestingly, poor performance in one measure did not necessarily reflect poor performance in another measure. For example, the 20 April cohort had relatively high cyprid and juvenile mortality (42.96 and $30.76 \%$, respectively) but also had the second highest mean juvenile growth rate $\left(28.02 \mu \mathrm{m} \mathrm{d}^{-1}\right)$.

Although previous studies have reported significant variation in mortality of new settlers, most studies do not distinguish cyprid mortality from mortality of juveniles (Hawkins \& Hartnoll 1982, Minchinton \& Scheibling 1993, Gosselin \& Qian 1996, and for review see Hunt \& Scheibling 1997). The results reported here suggest that the intensity of mortality during the premetamorphic period is equal to, and sometimes greater than, mortality during the early juvenile period. Although there was no significant positive relationship between cyprid and juvenile mortality in the present study, data reported by Connell (1961) for several daily cohorts of Semibalanus balanoides suggest a positive relationship between cyprid survival and overall survival of daily cohorts. Variation in cyprid mortality among daily cohorts of settlers may explain why some studies have found significant positive correlations between numbers of settlers or larval abundance and 
numbers of recruits (Connell 1985, Raimondi 1990, Minchinton \& Scheibling 1991) while other studies failed to find such correlation (Peterson \& Summerson 1992, Herrnkind \& Butler 1994). The significantly greater juvenile mortality on 12 April, which contrasts with the trend of relatively greater cyprid mortality compared to juvenile mortality in the other 4 cohorts, suggests that the mortality of attaching cyprids and juveniles may be affected by different factors.

In addition to external factors such as predation, desiccation, and dislodgement influencing cohort mortality, the physiological quality of the larvae at the time of settlement may differ among daily cohorts and, therefore, also contribute to pre-metamorphic mortality. Jarrett \& Pechenik (1997) previously found that daily cohorts arriving at the same study site during the same season as the present study differed significantly in cyprid organic content, a measure of the energy available to support metamorphosis. Unfortunately, measurements of cyprid organic content were not made for the cohorts monitored in the study reported here. By monitoring newly attached settlers both in the field and under controlled laboratory conditions, it should be possible to determine the relative influence of external factors and larval physiological quality on metamorphic success, juvenile growth, and juvenile survival in the field.

Acknowledgements. Thanks to 3 anonymous reviewers and B. Hentschel for helpful comments on early versions of the manuscript. This work was supported by grants to J.N.J. from Sigma Xi and the Lerner Gray Fund for Marine Research. Thanks to J. A. Pechenik and D. S. Wethey for advice and guidance and to the staff of Northeastern University's Marine Science Center, especially T. Maney.

\section{LITERATURE CITED}

Bertness MD (1989) Intraspecific competition and facilitation in a northern acorn barnacle population. Ecology 70 : $257-268$

Connell JH (1961) Effects of competition, predation by Thais lapillus, and other factors on natural populations of the barnacle Balanus balanoides. Ecol Monogr 31:61-104

Connell JH (1985) The consequences of variation in initial settlement vs. post-settlement mortality in rocky intertidal communities. J Exp Mar Biol Ecol 93:11-45

Fenaux L, Strathmann MF, Strathmann RR (1994) Five tests of food-limited growth of larvae in coastal waters by rates of development and form of echinoplutei. Limnol Oceanogr 39:84-98

Foster BA (1971) Desiccation as a factor in the intertidal zonation of barnacles. Mar Biol 8:12-29

Gosselin LA, Chia FS (1995) Characterizing temperate rocky shores from the perspective of an early juvenile snail: the

Editorial responsibility: Joseph Pawlik (Contributing Editor), Wilmington, North Carolina, USA main threats to survival of newly hatched Nucella emarginata. Mar Biol 122:625-635

Gosselin LA, Qian PY (1996) Early post-settlement mortality of an intertidal barnacle: a critical period for survival. Mar Ecol Prog Ser 135:69-75

Gosselin LA, Qian PY (1997) Juvenile mortality in benthic marine invertebrates. Mar Ecol Prog Ser 146:265-282

Hawkins SJ, Hartnoll RG (1982) Settlement patterns of Semibalanus balanoides in the Isle of Man (1977-1981). J Exp Mar Biol Ecol 62:271-283

Herrnkind WF, Butler MJ (1994) Settlement of spring lobster Panulirus argus in Florida: pattern without predictability. Crustaceana 67:46-64

Hunt HL, Scheibling RE (1997) Role of early post-settlement mortality in recruitment of benthic marine invertebrates. Mar Ecol Prog Ser 155:269-301

Jarrett JN, Pechenik JA (1997) Temporal variation in cyprid quality and juvenile growth capacity for an intertidal barnacle. Ecology 78:1262-1265; Erratum: Vol 78, p 1944

Menge BA (1976) Organization of the New England rocky intertidal community: role of predation, competition, and environmental heterogeneity. Ecol Monogr 46:355-393

Miller KM, Carefoot TH (1989) The role of spatial and size refuges in the interaction between juvenile barnacles and grazing limpets. J Exp Mar Biol Ecol 134:157-174

Minchinton TE, Scheibling RE (1991) The influence of larval supply and settlement on the population structure of barnacles. Ecology 72:1867-1879

Minchinton TE, Scheibling RE (1993) Variations in sampling procedure and frequency affect estimates of recruitment of barnacles. Mar Ecol Prog Ser 99:83-88

Morgan SG (1995) Life and death in the plankton: larval mortality and adaptation. In: McEdward L (ed) Ecology of marine invertebrate larvae. CRC Press, Boca Raton, FL, p 279-321

Paine RT (1974) Intertidal community structure. Experimental studies on the relationship between a dominant competitor and its principal predator. Oecologia 15:93-120

Pechenik JA (1999) On the advantages and disadvantages of larval stages in benthic marine invertebrate life cycles. Mar Ecol Prog Ser 177:269-297

Pechenik JA, Wendt DE, Jarrett JN (1998) Metamorphosis is not a new beginning. BioScience 48:901-910

Peterson CH, Summerson HC (1992) Basin-scale coherence of population dynamics of an exploited marine invertebrate, the bay scallop: implications of recruitment limitation. Mar Ecol Prog Ser 90:257-272

Petraitis PS (1983) Grazing patterns of the periwinkle and their effects on sessile intertidal organisms. Ecology 64:522-533

Pineda J (1994) Spatial and temporal patterns in barnacle settlement rate along a southern California rocky shore. Mar Ecol Prog Ser 107:125-138

Raimondi PT (1990) Patterns, mechanisms, consequences of variability in settlement and recruitment of an intertidal barnacle. Ecol Monogr 60:283-309

Roughgarden J, Pennington JT, Stoner D, Alexander S, Miller K (1991) Collisions of upwelling fronts with the intertidal zone: the cause of recruitment pulses in barnacle populations of Central California. Acta Oecol 12:35-51

Wethey DS (1984) Spatial pattern in barnacle settlement: day to day changes during the settlement season. J Mar Biol Assoc UK 64:687-698

Zar JH (1984) Biostatistical analysis, 2nd edn. Prentice Hall, Englewood Cliffs, NJ

Submitted: January 10, 2000; Accepted: April 14, 2000

Proofs received from author(s): September 1, 2000 